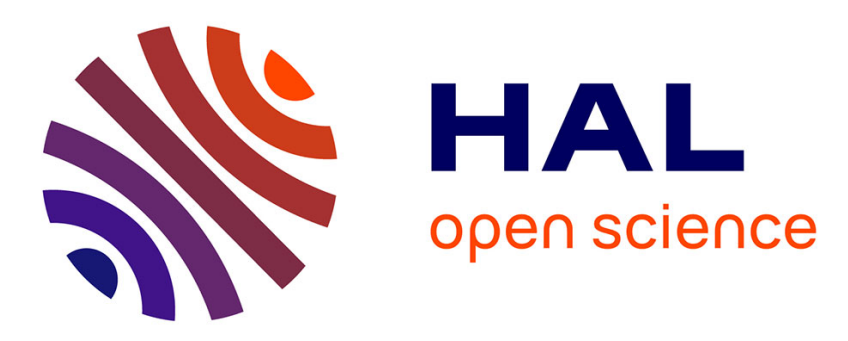

\title{
The temporal pattern of mortality responses to ambient ozone in the APHEA project.
}

E Samoli, A Zanobetti, J Schwartz, R Atkinson, A Le Tertre, C Schindler, L Pérez, E Cadum, J Pekkanen, A Paldy, et al.

\section{- To cite this version:}

E Samoli, A Zanobetti, J Schwartz, R Atkinson, A Le Tertre, et al.. The temporal pattern of mortality responses to ambient ozone in the APHEA project.. Journal of Epidemiology and Community Health, 2009, 63 (12), pp.960-n/a. 10.1136/jech.2008.084012 . hal-00484141

HAL Id: hal-00484141

https://hal.science/hal-00484141

Submitted on 18 May 2010

HAL is a multi-disciplinary open access archive for the deposit and dissemination of scientific research documents, whether they are published or not. The documents may come from teaching and research institutions in France or abroad, or from public or private research centers.
L'archive ouverte pluridisciplinaire HAL, est destinée au dépôt et à la diffusion de documents scientifiques de niveau recherche, publiés ou non, émanant des établissements d'enseignement et de recherche français ou étrangers, des laboratoires publics ou privés. 


\section{The Temporal Pattern of Mortality Responses to Ambient Ozone in the APHEA}

project.

E. Samoli ${ }^{1}$, A. Zanobetti ${ }^{2}$, J. Schwartz ${ }^{2}$, R. Atkinson ${ }^{3}$, A. LeTertre ${ }^{4}$, C. Schindler ${ }^{5}$, L. Pérez $^{6}$, E. Cadum ${ }^{7}$, J. Pekkanen ${ }^{8 a, 8 b}$, A. Paldy ${ }^{9}$, G. Touloumi ${ }^{1}$, K. Katsouyanni ${ }^{1}$

1. Dept of Hygiene, Epidemiology \& Medical Statistics, University of Athens, Greece 2. Harvard School of Public Health, Boston, U.S.A. 3. Community Health Sciences, University of London, U.K 4. Environmental Health Unit, National Institute of Public Health Surveillance, Paris, France. 5. Institute of Social and Preventive Medicine, University of Basel, Switzerland. 6. CREAL-Barcelona, Spain. 7. Center for Epidemiology and Environmental Health, Regional Agency for Environmental Protection, Turin, Italy. 8a. Department of Environmental Health, National Public Health Institute (KTL), Finland. 8b. School of Public Health and Clinical Nutrition, University of Kuopio, Finland. 9. National Institute of Environmental Health, Budapest, Hungary

Address correspondence to: Evangelia Samoli, Department of Hygiene and

Epidemiology, University of Athens Medical School, 75 Mikras Asias Street, 11527

Athens, Greece Tel:++30-210-7462085, Fax:++30-210-7462205,

e-mail: esamoli@med.uoa.gr

Keywords: Air pollution, distributed lag, mortality, mortality displacement, ozone.

Word count: 3874 


\section{ABSTRACT}

Background. We investigated the temporal pattern of effects of summertime ozone $\left(\mathrm{O}_{3}\right)$ in total, cardiovascular and respiratory mortality in 21 European cities participating in the APHEA-2 project, which is fundamental in determining the importance of the effect in terms of life loss.

Methods. Data from each city were analyzed separately using distributed lag models with up to 21 lags. City specific air pollution estimates were regressed on city specific covariates to obtain overall estimates and to explore sources of possible heterogeneity.

Results. We found stronger effects on respiratory mortality that extend to a period of two weeks. A $10 \mu \mathrm{g} / \mathrm{m}^{3}$ increase in $\mathrm{O}_{3}$ was associated with $0.36 \%$ (95\%CI: -0.21 , $0.94)$ increase in respiratory deaths for lag 0 and with $3.35 \%(95 \% \mathrm{CI}: 1.90,4.83)$ for lags 0-20. We also found significant adverse health effects of summer $\mathrm{O}_{3}$ (JuneAugust) on total and cardiovascular mortality that persist up to a week, but are counterbalanced by negative effects thereafter.

Conclusions. Our results indicate that studies on acute health effects of $\mathrm{O}_{3}$ using single day exposures may have overestimated the effects on total and cardiovascular mortality, but underestimated the effects on respiratory mortality. 


\section{What this paper adds.}

What is already known on this subject? Previous research has demonstrated adverse health effects of tropospheric ozone $\left(\mathrm{O}_{3}\right)$, a dominant pollutant in the photochemical air pollution mixture in urban centers, mainly encountered in the summer period. At the same time the results from air pollution epidemiological studies have been criticized as reflecting a small mortality displacement i.e. affecting only frail people who would have died within a few days anyway.

What does this study add? We investigated the temporal pattern of effects up to 21 days of summertime ozone $\left(\mathrm{O}_{3}\right)$ in total, cardiovascular and respiratory mortality in 21 European cities participating in the APHEA-2 project, which is fundamental in determining the importance of the effect in terms of life loss. We found that $\mathrm{O}_{3}$ effects are more prolonged for respiratory compared with cardiovascular deaths. Our results indicate that studies on acute health effects of $\mathrm{O}_{3}$ using single day exposures may have overestimated the effects on total and cardiovascular mortality, but underestimated the effects on respiratory mortality.

\section{Licence Statement}

The Corresponding Author has the right to grant on behalf of all authors and does grant on behalf of all authors, an exclusive licence (or non exclusive for government employees) on a worldwide basis to the BMJ Publishing Group Ltd and its Licensees to permit this article (if accepted) to be published in JECH editions and any other BMJPGL products to exploit all subsidiary rights, as set out in our licence (http://jech.bmj.com/ifora/licence.pdf)". 


\section{INTRODUCTION}

Previous research has demonstrated that the adverse health effects of tropospheric ozone $\left(\mathrm{O}_{3}\right)$, a dominant pollutant in the photochemical air pollution mixture in urban centers, are mainly encountered in the summer period [1-3]. This finding may be due to the higher concentration levels during the warmer period, since $\mathrm{O}_{3}$ is a strong oxidizing agent formed in the troposphere through a complex series of reactions involving the action of sunlight on nitrogen dioxide and hydrocarbons. Furthermore, $\mathrm{O}_{3}$ is very reactive, and its concentrations indoors are much lower than those outdoors, hence people are exposed to $\mathrm{O}_{3}$ outdoors. Thereafter the higher summer effect of $\mathrm{O}_{3}$ may also be a result of longer time spent outside in the warmer periods, or more commonly open windows, which results in higher exposures. Examination of specific causes of death indicates that a major part of the excess mortality related to elevated $\mathrm{O}_{3}$ levels is from cardiovascular and respiratory deaths. There are several underlying potential mechanisms: inflammation of pulmonary tissues, which can introduce a spectrum of mediators that also may alter cardiac function, or irritant receptor-mediated stimulation of parasympathetic pathways [4].

Earlier studies reported the association between daily deaths and $\mathrm{O}_{3}$ concentrations on the same day, a couple of days before death to up to a week before death [1,5-7]. At the same time the results from air pollution epidemiological studies have been criticized as reflecting a small mortality displacement i.e. affecting only frail people who would have died within a few days anyway. If this were true, and air pollution did not simultaneously increase the number of people who become frail, the size of the frail pool would decrease after the air pollution episode and this would result in a reduction in the number of deaths at longer lags. This mortality 
displacement effect has been described before, particularly for high temperatures [8]. Only Zanobetti \& Schwartz [9] have analyzed mortality displacement due to $\mathrm{O}_{3}$, in US cities and found no indication of a displacement pattern. Behavior and ventilation patterns, as well as co-pollutant exposures differ between the U.S., and other areas of the world, suggesting the importance of confirming these results in other locales.

The aim of this study was to investigate the temporal pattern (up to 21 days) in health effects of exposure to summertime $\mathrm{O}_{3}$. We present the results of analyses investigating the effects of $\mathrm{O}_{3}$ on mortality from all, cardiovascular and respiratory causes within the APHEA-2 project (Air Pollution and Health: a European Approach) which uses an extensive European database of cities spanning across the Continent.

\section{DATA AND METHODS}

APHEA-2 is a multi-center project including 30 cities across Europe and associated regions which studies short-term health effects of air pollution. Data were collected on daily counts of all-cause mortality excluding deaths from external causes (International Classification of Disease ICD-9>800), cardiovascular mortality (ICD-9: 390-459) and respiratory mortality (ICD-9:460-519). The data covered at least 3 consecutive years for each city within the years 1990 to 1997 . We analyzed daily deaths that occurred in June-August, so that all the lags were still in the warm season to ensure that any changes in the effect estimate reflect the effects of lags, and not possible weather effect especially in the upper and lower time limits of the data. In total, 571,798 deaths occurred in the studied cities during the summer period (JuneAugust). Details about the data have been published elsewhere [1].

Daily air pollution measurements were provided by the monitoring networks established in each town participating in the APHEA-2 project [10]. According to the 
APHEA protocol [10] we used the average daily concentration from fixed monitors that were not located at traffic sites and fulfilled certain data completeness criteria. We present results using the daily maximum of average exposure to $\mathrm{O}_{3}$ during 8 consecutive hours ( $8 \mathrm{~h})$, because this is the indicator recommended by the World Health Organization for reflecting the most health-relevant exposure to $\mathrm{O}_{3}$ [11]. In total, 21 cities spanning through Europe provided daily time series data for $\mathrm{O}_{3}(8 \mathrm{~h})$ concentrations. Time series data on daily temperature $\left({ }^{\circ} \mathrm{C}\right.$, daily mean $)$ and relative humidity (\%) were used to control for the potential confounding effects of weather.

Table 1 presents descriptive characteristics of the individual city data sets. The total population exposed is more than 60 million. The Netherlands is considered as one urban area because of its relative small size and dense population. The mean daily total number of deaths in the period analyzed ranged from 5 (in Geneva) to 331 (in the Netherlands). For respiratory mortality, mean daily counts ranged from $<1$ (e.g. in Ljubliana, Geneva) to 28 (Netherlands). The median levels of summer $\mathrm{O}_{3}$ ( $8 \mathrm{~h}$ max) ranged from $39 \mu \mathrm{g} / \mathrm{m}^{3}$ in Rome to $123 \mu \mathrm{g} / \mathrm{m}^{3}$ in Turin. There was substantial variability among cities in the levels of all pollutants, as well as in the mean daily temperature and humidity. 
Table 1. Characteristics of the city-specific data sets.

\begin{tabular}{|c|c|c|c|c|c|c|c|c|}
\hline & \multirow[t]{2}{*}{ Study period } & \multirow[t]{2}{*}{$\begin{array}{l}\text { No of } \\
\text { data }\end{array}$} & \multirow[t]{2}{*}{$\begin{array}{l}\text { Population } \\
\text { X } 1000\end{array}$} & \multicolumn{3}{|c|}{$\begin{array}{l}\text { Mean No of deaths } \\
\text { per day }\end{array}$} & \multirow{3}{*}{$\begin{array}{c}\mathbf{O}_{3}-8 \mathrm{~h}\left(\mu \mathrm{gg} / \mathrm{m}^{3}\right) \\
\text { Median } \\
\text { (27th-75th centile) } \\
100.8(88.0-114.5)\end{array}$} & \multirow{3}{*}{$\begin{array}{c}\begin{array}{c}\text { Mean summer } \\
\text { Temperature } \\
\left({ }^{\circ} \mathbf{C}\right)\end{array} \\
26.8 \\
\end{array}$} \\
\hline & & & & \multicolumn{3}{|c|}{ Total CVD Respiratory } & & \\
\hline Athens & 1/92-12/96 & 460 & 3,073 & 67 & 32 & 4 & & \\
\hline Barcelona & 1/91-12/96 & 552 & 1,644 & 36 & 13 & 3 & $75.9(63.7-91.5)$ & 23.3 \\
\hline Basel & $1 / 90-12 / 95$ & 552 & 360 & 9 & 4 & 1 & $83.5(63.2-111.4)$ & 19.0 \\
\hline Birmingham & $1 / 92-12 / 96$ & 460 & 2,300 & 54 & 24 & 7 & $55.0(42.6-66.8)$ & 15.7 \\
\hline Budapest & $1 / 92-12 / 95$ & 368 & 1,931 & 74 & 36 & 3 & $107.0(92.8-125.0)$ & 23.3 \\
\hline Geneva & $1 / 90-12 / 95$ & 552 & 317 & 5 & 2 & 0 & $90.9(71.9-115.6)$ & 19.5 \\
\hline Helsinki & $1 / 93-12 / 96$ & 644 & 828 & 17 & 8 & 1 & $57.2(46.2-70.1)$ & 15.8 \\
\hline Ljubljana & $1 / 92-12 / 96$ & 460 & 322 & 6 & 3 & 0 & $60.0(45.0-75.0)$ & 20.4 \\
\hline London & $1 / 92-12 / 96$ & 460 & 6,905 & 149 & 62 & 22 & $41.5(31.0-60.1)$ & 18.2 \\
\hline Lyon & $1 / 93-12 / 97$ & 460 & 416 & 8 & 3 & 1 & $81.8(60.3-105.5)$ & 20.8 \\
\hline Madrid & $1 / 92-12 / 95$ & 368 & 3,012 & 55 & 18 & 5 & $67.1(55.2-81.2)$ & 23.8 \\
\hline Milano & $1 / 90-12 / 96$ & 644 & 1,343 & 26 & 9 & 2 & $84.7(63.8-110.0)$ & 22.9 \\
\hline Netherlands & $1 / 90-9 / 95$ & 552 & 15,400 & 331 & 130 & 28 & $75.9(60.9-102.0)$ & 16.9 \\
\hline Paris & $1 / 91-12 / 96$ & 552 & 6,700 & 116 & 35 & 7 & $54.2(36.5-84.3)$ & 20.0 \\
\hline Prague & $2 / 92-12 / 96$ & 460 & 1,213 & 36 & 21 & 1 & $106.9(79.3-140.5)$ & 19.4 \\
\hline Rome & $1 / 92-12 / 96$ & 460 & 2,775 & 52 & 20 & 3 & $39.2(29.1-53.4)$ & 25.0 \\
\hline Stockholm & $1 / 90-12 / 96$ & 644 & 1,126 & 27 & 13 & 2 & $67.5(57.3-80.3)$ & 16.8 \\
\hline Teplice & $1 / 90-12 / 97$ & 736 & 625 & 17 & 10 & 1 & $72.3(52.0-96.6)$ & 18.2 \\
\hline Turin & $1 / 90-12 / 96$ & 644 & 926 & 19 & 8 & 1 & $123.2(95.8-146.6)$ & 23.5 \\
\hline Valencia & $1 / 94-12 / 96$ & 276 & 753 & 15 & 5 & 1 & $58.6(50.0-70.4)$ & 25.2 \\
\hline Zurich & $1 / 90-12 / 95$ & 552 & 540 & 12 & 5 & 1 & $92.1(68.5-119.4)$ & 18.0 \\
\hline
\end{tabular}

\section{Methods}

According to the APHEA-2 methodology [12], we used a hierarchic modeling approach. First, we fit regression models for each city separately to allow specific control for seasonal effects, weather and other potential confounders. We then used the individual city results in a second-stage analysis to obtain overall estimates and to investigate potential effect modifiers.

The $\mathrm{O}_{3}(8 \mathrm{~h})$-mortality associations for each city were investigated using Poisson regression models allowing for overdispersion. In order to control for season and long-term patterns we used dummy variables per month per year of data included in the analyses. To evaluate how sensitive our results were to the degree of seasonality control we also applied a natural spline function with 2 degrees of freedom per summer per year, as proposed by Zanobetti \& Schwatrz [9], and 3 degrees of freedom 
per summer per year. We did not control for influenza epidemics since previously published results $[8,13]$ have shown that these do not bias the association between air pollution and mortality, and since they do not occur in the summer. We used day of the week indicator variables, a linear term for humidity and an unconstrained distributed lag function (i.e. multiple linear lags [14]) for temperature to take into account the effect of temperature today and the previous three days (i.e. lags 0-3). We chose the number of lags for temperature based on previous results on the acute health effects of summer temperature in Europe, which showed that they extend only for a couple of days [15]. Our initial models included the $\mathrm{O}_{3}$ level of the day of death (lag 0 ) as a linear term. There was no significant temporal autocorrelation in the residuals of the city-specific models. We also present results on the effects of $\mathrm{O}_{3}$ exposure from the average of the same and previous day of death for comparability purposes with previously reported APHEA-2 effect estimates [1].

For the distributed lags analysis, we used the methodology proposed by Zanobetti \& Schwartz [9] and Zanobetti et al. [16]. Hence, we refit models using $\mathrm{O}_{3}$ on the day of death and up to the previous 20 days using an unconstrained distributed lag model, i.e. a model in which each lag is entered as a separate variable. If there is a mortality displacement effect, we expect to see negative associations between air pollution and deaths several days to weeks after exposure. The overall effect of $\mathrm{O}_{3}$, is the sum of the positive and negative estimates for all 21 days. We also applied a penalized quasi-likelihood to smooth the coefficients of the distributed lags [16]. This allows us to better examine the temporal pattern of the association with lag, since the unconstrained distributed lag model has too much collinearity to accurately estimate the individual lag effects, although it is precise enough to estimate the sum of all lagged effects. 
In the second-stage of the analysis, we assumed the city specific effect estimates to be normally distributed around an overall estimate. To see whether some of the variability in the city-specific estimates was explained by city characteristics, we regressed the city-specific effect estimates on potential effect modifiers (at city level), giving each city a weight inversely proportional to the variance of its effect estimate. If substantial $(\mathrm{p}<0.20)$ heterogeneity remained across city-results beyond the variation associated with the effect modifiers, random-effects regression models were applied. In these models, it was assumed that city-specific estimates were a sample of independent observations from a normal distribution with the same mean and with variances equal to the sum of the between-cities variance and the squared standard error of the city-specific estimate. The random variance component was estimated by iteratively reweighted least squares [17]. We applied the $X^{2}$ test and the $\mathrm{I}^{2}$ statistic, proposed by Higgins and Thompson [18], to examine heterogeneity. There was a general agreement between the two measures concerning the amount of observed heterogeneity attributed to the between cites variability.

Potential effect modifiers considered in the analysis included variables describing the air pollution level and mix in each city, the exposure and the health status of the population, the geographical area (North, Western, and Central-Eastern European cities) and the climatic conditions. There are very sparse comparable socio economic status (SES) indicators across the different countries in Europe available at city level. The only SES indicator available for all cities in this study was the percent of unemployment.

All models were fit in R v.2.6 (R development Core Team (2007), ISBN 3900051-07-0, URL http://www.R-project.org). 


\section{RESULTS}

Table 2 shows the overall percent increase in the daily mortality associated with an increase of $10 \mu \mathrm{g} / \mathrm{m}^{3}$ in the levels of the daily maximum 8-hour $\mathrm{O}_{3}$. Under the different lag structures except for lag 0 (for which there was no heterogeneity), there was significant to moderate $\left(\mathrm{X}^{2} \mathrm{p}<0.20\right.$ and $\left.\mathrm{I}^{2}>20 \%\right)$ heterogeneity among the estimates on total and cardiovascular mortality, while there was no heterogeneity in the $\mathrm{O}_{3}$ effects on respiratory deaths resulting in identical fixed and random effect estimates. We will comment on the random effects estimates, that take into account heterogeneity if present or coincide with fixed effects estimates in case of its absence. The unconstrained distributed lag model gave similar results to the penalized distributed lag. For total mortality when we considered only same day $\mathrm{O}_{3}$ exposure a $10 \mu \mathrm{g} / \mathrm{m}^{3}$ increase was associated with $0.28 \%(95 \% \mathrm{CI}: 0.07,0.48)$ increase in deaths. The effect of the average of two days' exposure was slightly lower but still significant while the sum of lags 0-20 was associated with a small decrease in the daily number of deaths. The same pattern was observed for cardiovascular mortality. Opposite results were found for respiratory mortality: the effect of $\mathrm{O}_{3}$ seemed to persist over the whole period examined (0-20 days). More specifically, a $10 \mu \mathrm{g} / \mathrm{m}^{3}$ increase in same day $\mathrm{O}_{3}$ yields a non-significant increase in respiratory mortality of $0.36 \%$ (95\%CI: $0.21,0.94)$ and a similar and significant increase after two day's exposure. The effect of $\mathrm{O}_{3}$ on respiratory deaths increased to $3.66 \%$ (95\%CI: $\left.2.25,5.08\right)$ and to $3.35 \%$ (95\%CI: 1.90, 4.83) when looking at the penalized and unconstrained distributed lag model, respectively, indicating a prolonged effect of $\mathrm{O}_{3}$ on respiratory deaths. 
Table 2. Estimated percent increase in mortality outcomes (and 95\% CIs) for a $10 \mu \mathrm{g} / \mathrm{m}^{3}$ increase in maximum 8 -h ozone during the June-August months, for the same day, the average of the same and previous day, the unconstrained distributed lag model for the sum of 0-20 days and the penalized distributed lag model (lags 0-20).

\begin{tabular}{|l|l|l|l|l|}
\hline & \multicolumn{2}{|c|}{ Fixed Effects } & \multicolumn{2}{c|}{ Random Effects } \\
\hline & \% increase & 95\%CI & \% increase & 95\%CI \\
\hline Total mortality & & & & \\
\hline Lag 0 & 0.28 & $0.11,0.45$ & 0.28 & $0.07,0.48$ \\
\hline Average lags 0-1 & 0.24 & $0.15,0.34$ & 0.22 & $0.08,0.35$ \\
\hline Sum lags 0-20, unconstrained & 0.01 & $-0.40,0.41$ & -0.54 & $-1.28,0.20$ \\
\hline Sum lags 0-20, penalized & 0.01 & $-0.41,0.42$ & -0.56 & $-1.30,0.19$ \\
\hline Cardiovascular mortality & & & & \\
\hline Lag 0 & 0.43 & $0.18,0.69$ & 0.37 & $0.05,0.69$ \\
\hline Average lags 0-1 & 0.33 & $0.19,0.48$ & 0.25 & $0.03,0.47$ \\
\hline Sum lags 0-20, unconstrained & -0.33 & $-0.93,0.29$ & -0.62 & $-1.47,0.24$ \\
\hline Sum lags 0-20, penalized & -0.32 & $-0.92,0.28$ & -0.57 & $-1.39,0.26$ \\
\hline Respiratory mortality & & & & \\
\hline Lag 0 & 0.36 & $-0.21,0.94$ & 0.36 & $-0.21,0.94$ \\
\hline Average lags 0-1 & 0.40 & $0.11,0.70$ & 0.40 & $0.11,0.70$ \\
\hline Sum lags 0-20, unconstrained & 3.35 & $1.90,4.83$ & 3.35 & $1.90,4.83$ \\
\hline Sum lags 0-20, penalized & 3.66 & $2.25,5.08$ & 3.66 & $2.25,5.08$ \\
\hline
\end{tabular}

In order to test for the robustness of the $\mathrm{O}_{3}$ effect we performed two sensitivity analyses. We used the same unconstrained distributed lag model as before, but instead of summing all the coefficients from lag 0 to lag 20 and meta-analyzing the sum across cities, we created two sums of coefficients in each city, from lag 0 to lag 3 and from lag 4 to lag 20 and meta-analyzed both sums across cities. We repeated the same analysis using a cutoff of 7 days, hence we created the sums for lags $0-6$ and lags 7-20. For all-cause mortality we found an effect size of $0.40 \%$ (95\% CI: -0.01 , 0.80 ) for lags $0-3$ and $-0.96 \%$ (95\%CI: $-1.5,-0.37$ ) for lags 4-20. Correspondingly, we found an effect size of $0.43 \%$ (95\% CI: $0.05,0.81$ ) for lags $0-6$ and $-0.99 \%$ (95\%CI: $1.5,-0.40$ ) for lags 7-20. These findings indicate a positive $\mathrm{O}_{3}$ effect on total mortality that persists up to a week, which is followed by negative effects thereafter. Since 
deaths from cardiovascular causes account for about $45 \%$ of the total number of deaths in the analyzed cities, the corresponding patterns for cardiovascular mortality followed the ones of total mortality.

Our results were also robust to the city-specific model choice. We tested excluding humidity from our models and our estimates changed only slightly. The estimate from the unconstrained distributed lag model for total daily number of deaths decreased to $-0.56 \%(95 \% \mathrm{CI}:-0.92,0.17)$, i.e. decreased by less than $4 \%$, indicating the stronger effect of temperature -compared with humidity- with regard to the model fit. Our results were also robust to the inclusion of a larger number of temperature lags, since when we allowed for up to 9 lags the estimate for respiratory mortality remained significant and decreased only by $10 \%$, while there was a similar increase for total mortality. We also applied a natural cubic spline with 2 degrees of freedom per summer per year of data to control for seasonality and long-term trends as suggested by Zanobetti \& Schwartz [9]. The total mortality estimate from the unconstrained distributed lag model increased slightly to $-0.47 \%$ (95\%CI: -1.18 , 0.24). There was a similar increase in the estimate of cardiovascular mortality and a decrease of comparable magnitude in respiratory mortality, not affecting the essence of the conclusions. When we applied a natural cubic spline with 3 degrees of freedom per summer per year of data to control for seasonality, the estimate from the unconstrained distributed lag model for total mortality increased to $-0.35 \%$ (95\%CI: $1.20,0.51)$, not altering the direction or the magnitude of the results.

Figure 1 presents the percentage increase in the daily number of all (A) and respiratory (B) deaths and their $95 \% \mathrm{CI}$ associated with an increase of $10 \mu \mathrm{g} / \mathrm{m}^{3}$ in $\mathrm{O}_{3}$ levels during the June-August months in each city and in all cities, as estimated from the models using mean exposure of two days (triangles represent average of same and 
previous day) and from the smooth distributed lag model (squares). The statistically significant estimated increases in total mortality per $10 \mu \mathrm{g} / \mathrm{m}^{3}$ increase in summer $\mathrm{O}_{3}$ average of lags $0-1$ ranged from $0.30 \%$ in the Netherlands to $0.65 \%$ in Athens, while the corresponding increases from the distributed lag model ranged from $-4.75 \%$ in Milan to $1.02 \%$ in the Netherlands. The plot demonstrates the heterogeneity of the total mortality results especially under the distributed lag model. As shown in Table 2 the average of the same and previous day of $\mathrm{O}_{3}$ exposure yields larger and comparably less heterogeneous effect estimates for total mortality, while the opposite is true for respiratory mortality. The larger cities tend to have the smaller confidence intervals (such as the Netherlands, London and Paris).

Figure 2 presents the shape of the smoothed distributed lag pattern for total mortality across the 21 European cities. Each triangle represents the percent increase in total mortality per $10 \mu \mathrm{g} / \mathrm{m}^{3}$ increase in $\mathrm{O}_{3}$ for each of the 21 lags. We found the highest effect at lag 0 declining to zero by day 4 . The values between lags 5 and 17 are almost zero while the last lags have high confidence intervals that make extrapolation unreliable. The temporal pattern between $\mathrm{O}_{3}$ and cardiovascular mortality is almost identical to the one for total mortality.

Figure 3 presents the corresponding plot for respiratory mortality. The highest effect is observed in the first two days while the effect of $\mathrm{O}_{3}$ persists up to lag 12 . Again the next four values are almost zero while the last lags are poorly estimated. However, the whole curve has larger confidence intervals compared with the plot for total mortality due to the smaller death counts. The plot illustrates the extended effect of $\mathrm{O}_{3}$ on respiratory mortality as also indicated by the results in Table 2 .

We investigated the observed heterogeneity in the estimates of the short-term effects of summer $\mathrm{O}_{3}$ on total and cardiovascular mortality by examining potential 
effect modifiers in second stage regression models. For the distributed lag effect estimates and for respiratory mortality we did not investigate effect modification, as $\mathrm{O}_{3}$ did not have an overall significant effect on daily total and cardiovascular mortality or there was no heterogeneity in the estimates. When investigating the source of heterogeneity in the association between $\mathrm{O}_{3}$ and total and cardiovascular mortality using the average of two day's exposure the only significant effect modifiers were the mean level of $\mathrm{PM}_{10}$ for total mortality and the age structure of the population for cardiovascular mortality. More specifically the effect of summer $\mathrm{O}_{3}$ on total mortality was higher in cities with lower levels of $\mathrm{PM}_{10}$; on cardiovascular mortality the effect was greater for cities with a smaller proportion of elderly and the association was inverse in cities with younger populations.

\section{DISCUSSION}

In the last few years, several meta-analyses on acute mortality and ozone have been published, and their results showed (quite consistently) significant increases in risks for the warm season. For all-causes of mortality the reported increase (per 10 $\mu \mathrm{g} / \mathrm{m}^{3}$ increase of $\mathrm{O}_{3}$ ) has swayed among $0.1 \%$ [19-21], 0.2\% [22] and 0.3\% [1-3, 6, 23-24]. For cardiovascular causes the magnitude of effects ranged between an increase of $0.4 \%[1,6,23]$ and $0.2 \%$ [24], but the Italian meta-analysis considered a different period (May to September).

Our study investigated a more prolonged time period of effects. We have found significant adverse health effects of summer $\mathrm{O}_{3}$ (June-August) on total and cardiovascular mortality that persist up to a week. We found stronger effects on respiratory mortality that extend to a period of two weeks. These findings complement those previously reported from APHEA-2 [1], where an increase of $10 \mu \mathrm{g} / \mathrm{m}^{3}$ in $\mathrm{O}_{3}$ - 
8h, average of lags 0 and 1, in the warm period of the year (April through September) was associated with $0.31 \%, 0.46 \%$ and $1.13 \%$ increases in total, cardiovascular and respiratory mortality, respectively. Our estimates for the same period of exposure (average of same and previous day) are slightly lower. This may be attributed to the difference between the months analyzed as well as to the methodology applied within

\section{APHEA-2.}

When we examined models for the cumulative effect of 21 days of $\mathrm{O}_{3}$ exposure either using an unconstrained or a penalized smooth distributed lag model we found no effect of summer $\mathrm{O}_{3}$ on total and cardiovascular mortality but a significant adverse effect on respiratory mortality. Thus, there seems to be mortality displacement in the effects of $\mathrm{O}_{3}$ on total and cardiovascular but not on respiratory mortality. Zanobetti and Schwartz [9], in their investigation of mortality displacement in the association of $\mathrm{O}_{3}$ and mortality in 48 U.S. cities found effect size estimates for total, cardiovascular and respiratory mortality after 21 lags (0-20 days) that were somewhat larger (though non-significant except for total mortality) than those using a single day's concentration, indicating no evidence of short term mortality displacement. Although these findings indicate a different magnitude of exposureresponse between U.S and Europe, the comparison of the smooth plots for the two regions produced for the association between summer $\mathrm{O}_{3}$ and total mortality reveals a similar shape slightly shifted upwards in the U.S. Hence the overall pattern is quite similar - both studies find the summer $\mathrm{O}_{3}$ effect on total mortality is in the first week. Several factors may explain the upward shift of the curve in the U.S. cities. First, the U.S. cities presented in the Zanobetti and Schwartz study [9] seem to have higher $\mathrm{O}_{3}$ levels compared to the European ones in our analysis. Another difference between the U.S and the European results is that the latter are more heterogeneous 
than the former. In that context we have tried to identify city-specific characteristics that may contribute to the observed heterogeneity especially in the $\mathrm{O}_{3}$-total mortality association. Since there was moderate heterogeneity when we considered two days' exposure, the only effect modifier identified for total mortality was the mean level of $\mathrm{PM}_{10}$ and for cardiovascular mortality the age structure of the population, expressed either as the proportion above 75 or inversely the proportion under 15 . The higher effects of two days' $\mathrm{O}_{3}$ on total mortality in cities with lower PM level is unclear and may reflect the air pollution mix; while the higher effect in younger populations may reflect exposure patterns in the sense that during hot days on which $\mathrm{O}_{3}$ concentration is higher elderly people tend to stay indoor or even leave the urban areas. The effect modification patterns identified were not driven by outliers in the distribution of the variables under investigation. The exploration of effect modification was limited by the number of variables that extended across the full data set. Although previous investigation of effect modification patterns in the effects of $\mathrm{O}_{3}$ on total and cardiovascular mortality [1] indicated the standardized mortality rate and the geographical area as modifiers, respectively, we have not replicated these findings in our restricted summer period analysis.

Our analysis is constrained by the nature of time-series studies that can only extend up to about a monthly time-period. Since there is evidence of adaptation to $\mathrm{O}_{3}$ with reduced effects on lung function [25] there is ground to believe that any effect would occur in the first weeks. Nevertheless, it is not possible to test such a hypothesis within this framework. Another inherent disadvantage of time-series studies is exposure misclassification. Especially for the analysis of $\mathrm{O}_{3}$ effects, the location of the monitoring stations may be important due to the scavenging characteristic of the pollutant. However, even if the absolute levels in each city may 
be affected by the monitoring station's location (and consequently the ranking of the cities according to the pollutant's level may not reflect the reality), the day-to-day variability is unlikely to be affected. Therefore, our results, based on the analysis of daily variability, should not have been affected. Finally, we have not controlled for $\mathrm{PM}_{10}$ since there is good evidence that this would not confound the association [1, 26].

We found that ozone effects are more prolonged for respiratory compared with cardiovascular deaths. It is interesting to note that Goodman et al. [27] have reported similar time patterns for exposure to particulate pollution and indicated a different time response for cardiovascular mortality compared with respiratory mortality, where cardiovascular mortality occurred within the first few days of exposure, whereas respiratory mortality showed a lag of up to two weeks. This makes some sense, since air pollution can be associated with the triggering of cardiovascular events [28], while exacerbation of respiratory infections would be expected to take more time. Wheeler et al. [29] found direct evidence of heterogeneity in the autonomic response to ambient pollution that is dependent on the underlying health status of the study population. Mudway et al. [30] point out that the rules that govern the balance between beneficial and detrimental interactions between $\mathrm{O}_{3}$ and antioxidants in the lung lining fluid compartment are not well established but these may contribute in part to sensitivity. Hence, the biological mechanisms responsible for the adverse health effects of $\mathrm{O}_{3}$, particularly on the basis of individual susceptibility, are still unclear. In conclusion, there was indication of mortality displacement for total and cardiovascular mortality but not for respiratory. The extended follow-up effects of $\mathrm{O}_{3}$ on respiratory mortality were more than three times greater than acute effects previously reported. Our results indicate that studies on acute health effects of $\mathrm{O}_{3}$ 
using single day exposures may have underestimated the effects of air pollution on respiratory mortality.

\section{ACKNOWLEDGMENTS:}

This work was funded through two grants from the European Commission

(E.C.) Environment and Climate Programme (Contract numbers: ENV4-CT97-0534 and QLK4-CT-2001-30055).

The authors declare no competing interests. 


\section{REFERENCES}

1) Gryparis A, Forsberg B, Katsouyanni K, et al. Acute effects of ozone on mortality from the "air pollution and health: European approach" project. Am J Respir Crit Care Med 2004; 170(10): 1080-1087.

2) Ito K, De Leon SF, Lippmann M. Associations between ozone and daily mortality: analysis and meta-analysis. Epidemiology 2005; 16(4): 446-457.

3) Levy JL, Chemerynski SM, Sarnat JA. Ozone exposure and mortality: an empiric bayes metaregression analysis. Epidemiology 2005; 16(4): 458-468.

4) Watkinson WP, Campen MJ, Nolan JP, et al. Cardiovascular and systemic responses to inhaled pollutants in rodents: effects of ozone and particulate matter. Environ Health Perspect 2001; 109 (4): 539-546.

5) Huang Y, Dominici F, Bell ML. Bayesian hierarchical distributed lag models for summer ozone exposure and cardio-respiratory mortality. Environmentrics 2005;

16: $547-562$.

6) Bell ML, Dominici F, Samet JM. A meta-analysis of time-series studies of ozone and mortality with comparison to the national Morbidity, Mortality and Air Pollution Study. Epidemiology 2005; 16(4): 436-445.

7) Bell ML, Dominici F. Effect Modification by Community Characteristics on the Short-term Effects of Ozone Exposure and Mortality in 98 US Communities. Am J Epidemiology 2008; 167: 986-997.

8) Braga A, Zanobetti A. Do respiratory epidemics confound the association between air pollution and daily deaths? Eur Respir J 2000; 16: 723-726.

9) Zanobetti A, Schwartz J. Mortality displacement in the association of ozone with mortality: An analysis of 48 US cities. Am J Respir Crit Care Med 2008; 177(2): 184189. 
10) Katsouyanni K, Touloumi G, Samoli E, et al. Confounding and effect modification in the short-term effects of ambient particles on total mortality: results from 29 European cities within the APHEA2 project. Epidemiology 2001; 12: 521531.

11) WHO (World Health Organization). Air Quality Guidelines for Europe. Second Edition. WHO Regional Publications European Series No 91, Copenhagen. 2000.

12) Touloumi G, Atkinson R, Le Tertre A, et al. Analysis of health outcome time series data in epidemiological studies. Environmetrics 2003; 15: 101-117.

13) Touloumi G, Samoli E, Quenel P, et al. Short-term effects of air pollution on total and cardiovascular mortality: the confounding effects of influenza epidemics. Epidemiology 2005; 16: 49-57.

14) Schwartz J. The distributed lag between air pollution and daily deaths. Epidemiology 2000; 11(3): 320-326.

15) Baccini M., Biggeri A, Accetta G, et al. Effects of apparent temperature on summer mortality in 15 European cities: results of the PHEWE project. Epidemiology 2008; 19(5): 711-719.

16) Zanobetti A, Wand MP, Schwartz J, et al. Generalised additive distributed lag models: quantifying mortality displacement. Biostatistics 2000; 1: 279-292.

17) Berkey CS, Hoaglin DC, Mosteller F, et al. A random-effects regression model for meta-analysis. Stat Med 1995; 14: 395-411.

18) Higgins JP, Thompson SG. Quantifying heterogeneity in a meta-analysis. Stat Med 2002; 21: 1539-1558.

19) Thurston GD, Ito K. Epidemiological studies of acute ozone exposures and mortality. J Expo Anal Environ Epidemiol 2001; 11(4): 286-294. 
20) Stieb DM, Judek S, Burnett RT. Meta-analysis of time-series studies of air pollution and mortality: effects of gases and particles and the influence of cause of death, age, and season. J Air Waste Manag Assoc 2002; 52(4):470-484.

21) Bell ML, McDermott A, Zeger SL, et al. Ozone and short-term mortality in 95 US urban communities, 1987-2000. JAMA 2004; 292(19): 2372-2378.

22) Schwartz J. How sensitive is the association between ozone and daily deaths to control for temperature? Am J Respir Crit Care Med 2005; 171(6):627-631.

23) Anderson HR, Atkinson R, Peacock J, et al. Meta-analysis of time-series studies and panel studies of particulate matter (PM) and ozone (O3): report of a WHO task group. Copenhagen, WHO Regional Office for Europe. 2004. (document EUR/04/5042688; http://www.euro.who.int/document/E82792.pdf, accessed 1 July 2008).

24) Biggeri A, Bellini P, Terracini B. Meta-analysis of the Italian studies on shortterm effects of air pollution - MISA 1996-2002. Epidemiol Prev 2004; 28(S4-5):4100 (in Italian).

25) Zanobetti A, Schwartz J. Is there adaptation in the ozone-mortality relationship: A multi-city case crossover analysis. Environ Health 2008; 30: 7-22.

26) Bell ML, Kim JY, Dominici F. Potential confounding of particulate matter on the short-term association between ozone and mortality in multisite time-series studies. Environ Health Perspect 2007; 115(11): 1591-1595.

27) Goodman PG, Dockery DW, Clancy L. Cause-specific mortality and the extended effects of particulate pollution and temperature exposure. Environ Health Perspect 2004; 112(2): 179-185. 
28) Peters A, von Klot S, Heier M, et al; Cooperative Health Research in the Region of Augsburg Study Group. Exposure to traffic and the onset of myocardial infarction. N Engl J Med 2004; 351(17): 1721-1730.

29) Wheeler A, Zanobetti A, Gold DR, et al. The relationship between ambient air pollution and heart rate variability differs for individuals with heart and pulmonary disease. Environ Health Perspect 2006; 114 (4): 560-566.

30) Mudway IS, Kelly FJ. Ozone and the lung: a sensitive issue. Mol Aspects Med 2000;21(1-2):1-48. 


\section{FIGURE LEGENDS}

Figure1. City-specific and overall percent increase (and 95\% CIs) in total (A) and respiratory (B) mortality per $10 \mu \mathrm{g} / \mathrm{m}^{3}$ increase in $\mathrm{O}_{3}(8 \mathrm{~h}$ ) during the June-August months. Triangles represent the effect of the average of lags 0 and 1 and squares the smooth distributed lag effect.

Figure 2. Plot of the combined smooth distributed lag in 21 European cities during the June-August months. The triangles represent the percent increase in total mortality per $10 \mu \mathrm{g} / \mathrm{m}^{3}$ increase in $\mathrm{O}_{3}(8 \mathrm{~h})$, and the shaded area represents the $95 \%$ confidence intervals.

Figure 3. Plot of the combined smooth distributed lag in 21 European cities during the June-August months. The triangles represent the percent increase in respiratory mortality per $10 \mu \mathrm{g} / \mathrm{m}^{3}$ increase in $\mathrm{O}_{3}(8 \mathrm{~h})$, and the shaded area represents the $95 \%$ confidence intervals. 
A) Total mortality

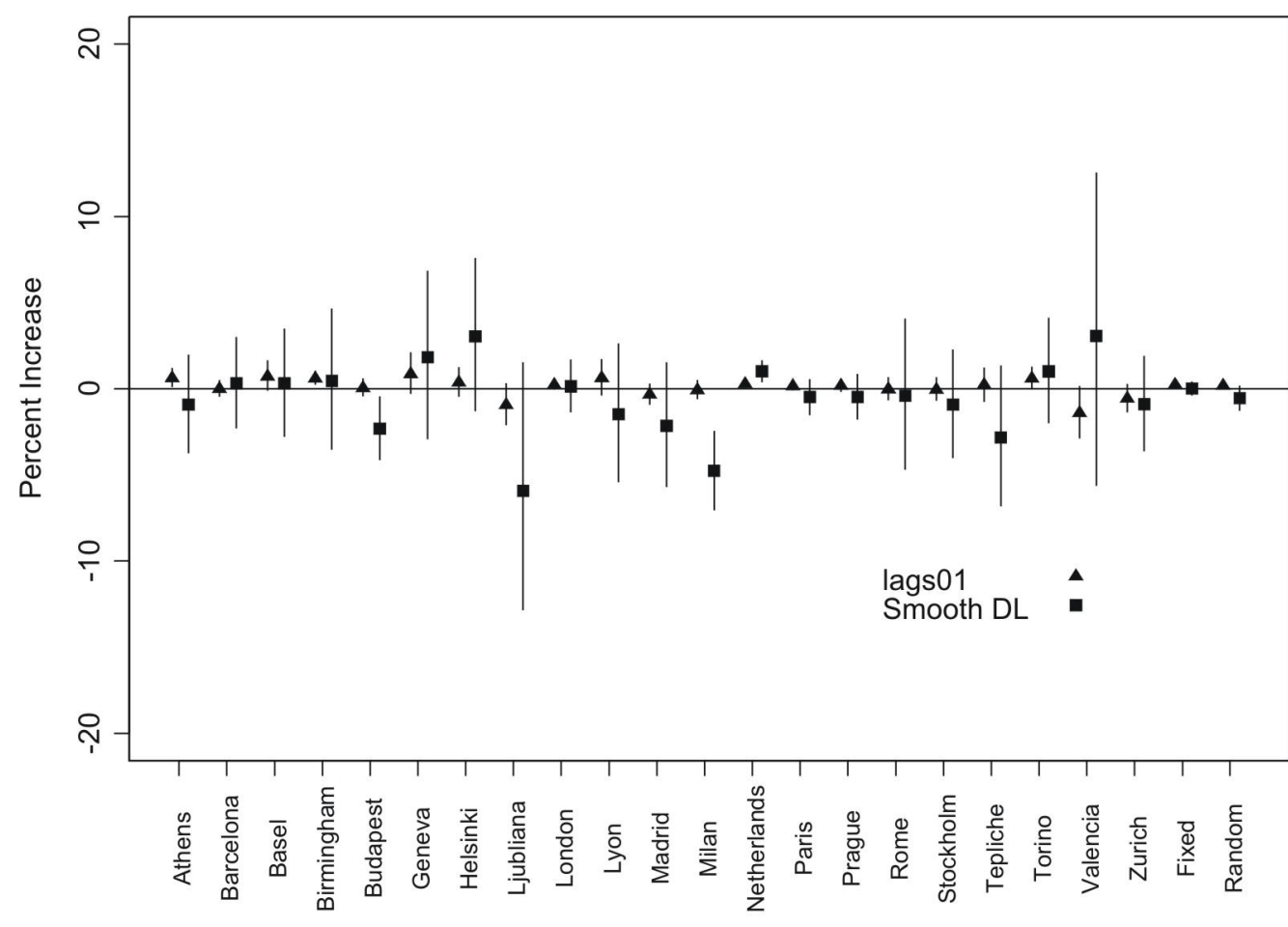

B) Respiratory mortality

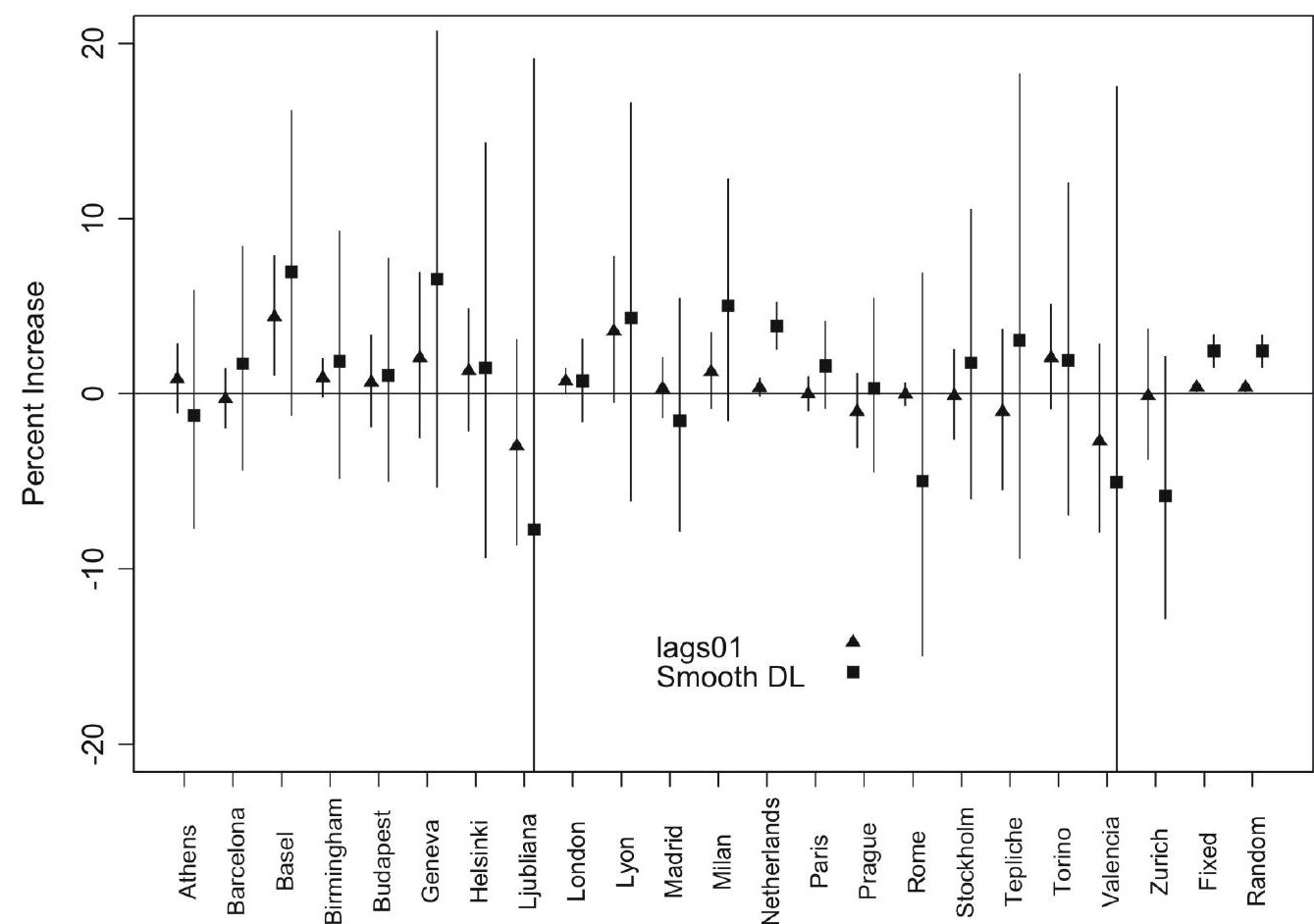




\section{Total mortality: Smooth Distributed Lag in 21 cities}

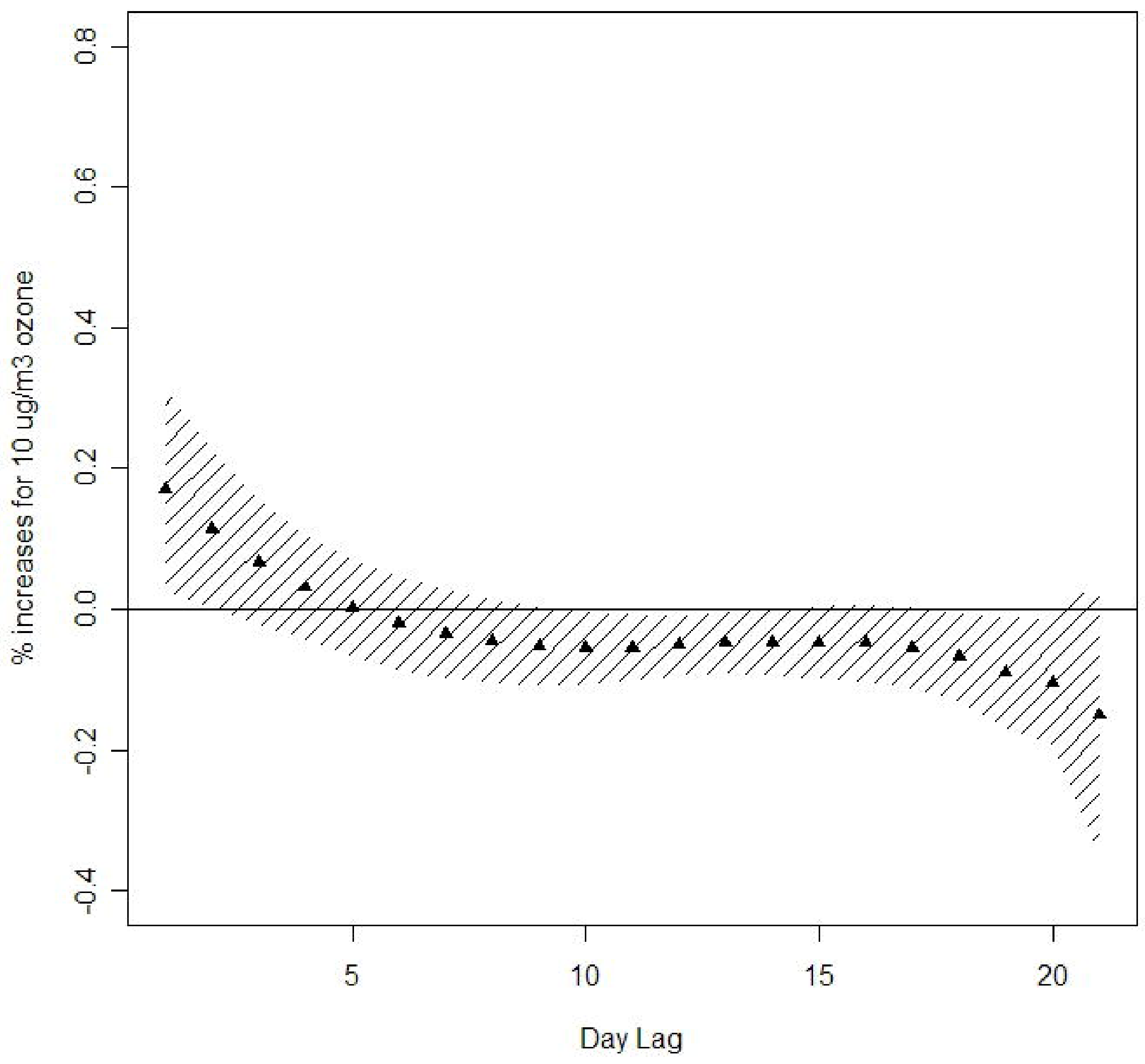




\section{Respiratory mortality: Smooth Distributed Lag in 21 cities}

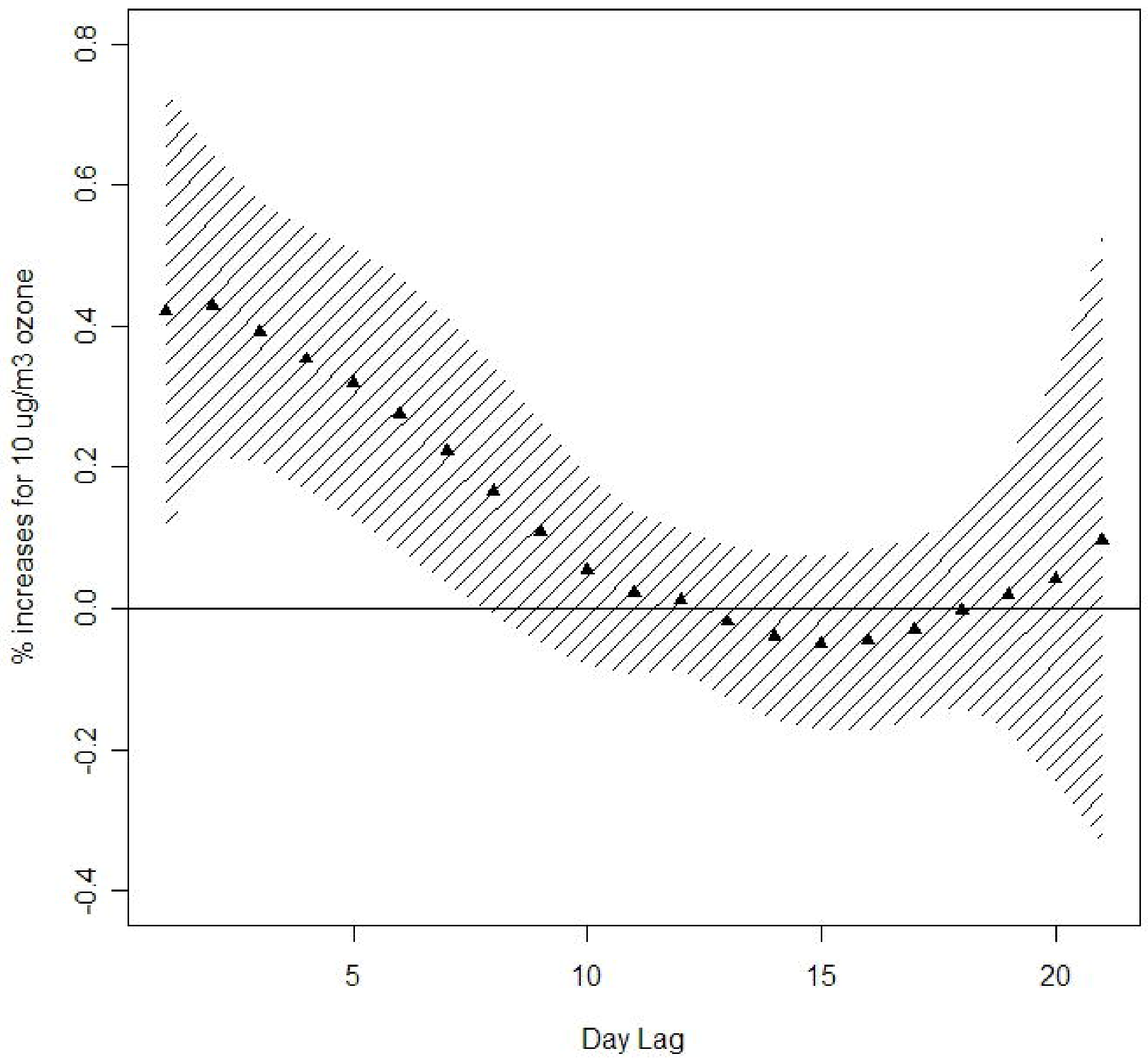

